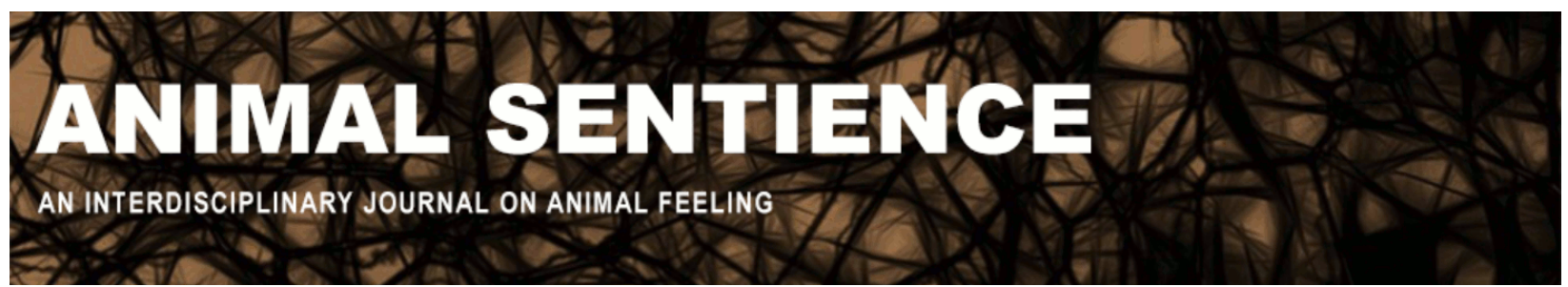

Racine, Timothy P. (2018) An adaptationist perspective on animal suicide. Animal Sentience 20(12)

DOI: $10.51291 / 2377-7478.1300$

Date of submission: 2018-01-22

Date of acceptance: 2018-01-26

(c)

This article has appeared in the journal Animal

Sentience, a peer-reviewed journal on animal

cognition and feeling. It has been made open access,

free for all, by WellBeing International and deposited

in the WBI Studies Repository. For more information,

please contact

wbisr-info@wellbeingintl.org.

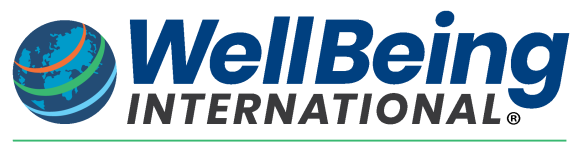

SOLUTIONS FOR PEOPLE, ANIMALS AND ENVIRONMENT 


\title{
An adaptationist perspective on animal suicide
}

Commentary on Peña-Guzmán on Animal Suicide

\author{
Timothy P. Racine \\ Department of Psychology \\ Simon Fraser University
}

\begin{abstract}
Peña-Guzmán's discussion of suicide in nonhuman animals has broad implications. In this commentary, I focus on the logical relation between suicide and intention. Proximate cause must be distinguished from ultimate function in explanations of suicide. I briefly discuss two adaptationist accounts of suicidal behavior.
\end{abstract}

Tim Racine is Professor of History, Quantitative and Theoretical Psychology at Simon Fraser University, Burnaby, BC, Canada. His research is on the use of conceptual analysis and evolutionary theory in psychology, and the development of social cognition in human and nonhuman primates.

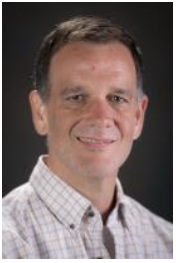

www.sfu.ca/psychology/about/people/profiles/tracine.html

Peña-Guzmán's (2017) discussion of suicide in nonhuman animals has potential implications for theories of suicide, the understanding of nonhuman behavioral capacities, and even concepts of personhood. In this commentary, I focus on a key issue that underscores the difficulty of determining what "counts" as suicide in nonhuman animals, namely, the logical relation between suicide and intention. I extend Peña-Guzmán's article by considering the need to distinguish proximate cause from ultimate (evolutionary) function in explanations of suicide. I then consider two adaptationist accounts of suicidal behavior and discuss their relevance for Peña-Guzmán's argument.

Peña-Guzmán discounts the definitional importance of intention in suicide by arguing that free will is a thorny topic with metaphysical baggage and that intention is often understood in causal/mental-representational terms. Let's step back though and consider whether it would make sense to state that a human (or nonhuman) animal accidentally committed suicide. I suggest that this would be a very odd use of language; if the action was not intentional, we would not consider it suicide. The ontology of free will notwithstanding, this speaks to the role of intention in the application of the concept of suicide (see also commentary by Preti, 2018). As Peña-Guzmán notes, however, intention need not be construed as a causal prior "internal" event; the work of Leavens and colleagues, for example (Leavens, Bard, \& Hopkins, 2017, see also, Leavens, Racine, \& Hopkins, 2009), which Peña-Guzmán cites, is a reminder that the so-called representational theory of mind is but one framework for making sense of human and nonhuman behaviors. However, pointing this out does not make intention independent of suicidality. Rather, it invites us to consider behavioral grounds when making attributions of intentionality; the potential mistake would be seeing intention as having to be some sort of prior mental act, or the like. 
Peña-Guzmán's discussion of the parallels between human and nonhuman selfdestructive behavior seems to skate around this central issue of intentionality. Given that an implication of his target article is the evolutionary continuity of suicidal behavior, a more direct way to make this case might be to consider the ultimate function of suicide. As Peña-Guzmán notes, evolutionary theories have been used to explain self-harm behaviors in nonhuman animals, often without reference to suicide. For example, an implication of inclusive fitness theory is that one will sacrifice one's life if it would benefit the reproductive prospects of those with whom one shares genes. Although this might explain the adaptive function of self-sacrifice, it cannot, as Peña-Guzmán remarks, distinguish suicidal from nonsuicidal behaviors and is therefore of limited relevance in the present discussion. It also runs afoul of the intentionality criterion mentioned earlier. After all, as Peña-Guzmán (p. 8, emphasis original) remarks, "there is a difference between how we explain the behavior and what we call it." It is also important to recognize that appeals to proximate and ultimate cause should not be understood as competing explanations of a behavior (MacDougall-Shackleton, 2011).

Attributing an ultimate function for a behavior typically amounts to the claim that the behavior was adaptive in some ancestral context. As noted, appeals to inclusive fitness (or, derivatively, kin selection) are not sufficient on their own; what is needed is an adaptationist account of suicidality proper. If such an account existed and were plausible, then it could be applied to human and nonhuman animals, supporting the Darwinian continuity that PeñaGuzmán argues for in his target article.

Given that suicide is relatively common and heritable in humans (for a review, see Turecki, 2001), we can presume it has a potential adaptive function and we can go on to test various adaptationist hypotheses. Indeed, different adaptationist accounts have been advanced to explain its prevalence in humans. De Catanzaro (1995), for example, points out that suicide occurs at a higher rate when individuals are less likely to reproduce and more likely to be a burden to their families. Evoking inclusive fitness, de Catanzaro argues that these individuals are also less able to promote their genes (see also commentary by Preti, 2018). An alternative (but not necessarily competing) hypothesis has been put forward by Tanaka and Kinney (2011), who argue that the evolutionary function of suicide is to reduce the risk of transmitting infections to kin. Their evidence is that immune dysfunction increases the likelihood of experiencing negative mental health outcomes associated with suicide and that suicide is more common in occupations associated with immune dysfunction.

Although either, or both, of these hypotheses might capture something of the ancestral condition of anatomically modern humans, they leave open the question of whether these explanations would automatically support the continuity thesis. Given the definitional concerns mentioned earlier, the actual proximate suicidal act, whatever its evolutionary function, must presumably be intended by the actor. Since evoking intention need not evoke causally prior representational capacities, it is here that human "theory of mind" capacities might be required for behavior to be considered suicidal.

As Peña-Guzmán notes, great apes do pass mirror self-recognition tests. However, mirror self-recognition indexes a fairly limited mentality. Although chimpanzees have been shown to understand intentions in competitive situations, they do not seem to understand intentions in general (e.g., Tomasello, 2014). For this reason, among others, it is perhaps unsurprising that many of the examples of suicide in nonhuman animals are anecdotal. Although there are clear 
instances of animals engaging in self-harming behaviors, none clearer perhaps than alarm calling in vervet monkeys, there are few unambiguous examples of self-directed lethal behaviors. Therefore, although I applaud Peña-Guzmán's attempt to broaden the conceptual space for considering the possibility of suicide and injecting some Darwinian continuity into these discussions, I think claims of nonhuman animal suicide should still be met with due skepticism.

\section{References}

de Catanzaro, D. (1995). Reproductive status, family interactions, and suicidal ideation: Surveys of the general public and high-risk groups. Ethology \& Sociobiology, 16, 385-394.

Leavens, D.A., Bard, K.A., \& Hopkins, W.D. (2017). The mismeasure of ape social cognition. Animal Cognition, 1-18.

Leavens, D.A., Racine, T.P., \& Hopkins, W.D. (2009). The ontogeny and phylogeny of non-verbal deixis. In R. Botha \& C. Knight (Eds.), The cradle of language. Volume 1: Multidisciplinary perspectives (pp. 142-165). Oxford, UK: Oxford University Press.

MacDougall-Shackleton, S.A. (2011). The levels of analysis revisited. Philosophical Transactions of the Royal Society of London Series B: Biological Sciences, 366(1594), 2076-2085.

Peña-Guzmán, D.A. (2017). Can nonhuman animals commit suicide? Animal Sentience 20(1).

Preti, A. (2018). Animal suicide: Evolutionary continuity or anthropomorphism? Animal Sentience 20(10).

Tanaka, M., \& Kinney, D.K. (2011). An evolutionary hypothesis of suicide: Why it could be biologically adaptive and is so prevalent in certain occupations. Psychological Reports, 108, 997-992.

Tomasello, M. (2014). A natural history of human thinking. Cambridge, MA: Harvard University Press.

Turecki, G. (2001). Suicidal behavior: Is there a genetic predisposition? Bipolar Disorders, 3, 335349. 